\title{
Clinical use of crizotinib for the treatment of non-small cell lung cancer
}

This article was published in the following Dove Press journal:

Biologics:Targets and Therapy

29 April 2013

Number of times this article has been viewed

\author{
Patrick J Roberts \\ Lineberger Comprehensive Cancer \\ Center, University of North Carolina \\ at Chapel Hill, Chapel Hill, NC, USA
}

Correspondence: Patrick J Roberts

Lineberger Comprehensive

Cancer Center, University

of North Carolina School

of Medicine, 450 West Drive,

CB 7295, Chapel Hill, NC

27599-7295, USA

$\mathrm{Tel}+$ I 9199669755

Fax +19199668212

Email patrick_roberts@unc.edu

\begin{abstract}
Discoveries over the last decade have fundamentally transformed the way we define lung cancer. Gone are the days of the simple binary classification system of non-small cell lung cancer (NSCLC) and small cell lung cancer. Today, accurate identification of the histological and molecular subtype of NSCLC is required for selecting standard cytotoxic chemotherapy and targeted therapies. The identification of anaplastic lymphoma kinase $(A L K)$ rearrangements in $5-7 \%$ of NSCLC patients and the rapid clinical development of crizotinib for these patients is the most recent clinical example necessitating the proper identification of the molecular characteristics of NSCLC for treatment decisions. The discovery of $A L K$ rearrangements in NSCLC serendipitously coincided with the development of crizotinib for other $A L K$ or MET driven malignancies. The clinical development of crizotinib for $A L K$-positive NSCLC patients has been an amazing success story of translational medicine that relied on the prior clinical experience of other targeted predecessors (i.e. erlotinib in EGFR mutant NSCLC) and a compound ready for clinical development to gain expedited FDA approval. This review discusses the clinical development and use of crizotinib in NSCLC.
\end{abstract}

Keywords: Xalkori, Non-Small Cell Lung Cancer, $A L K, E M L 4-A L K$, HSP90 inhibitors, ROS1, MET

\section{Introduction}

Lung cancer is the leading cause of cancer mortality in the US and worldwide. ${ }^{1,2}$ Over the last decade we have witnessed several discoveries that have fundamentally transformed the way we define lung cancer. Historically, lung cancer histology has predominantly relied on a simplistic binary classification that divided lung cancer cases into either non-small cell lung cancer (NSCLC) or small cell lung cancer. Today, accurate identification of the histological and molecular subtype of NSCLC has become crucial in selecting standard cytotoxic chemotherapy and targeted therapies. This was first demonstrated when the interactions between NSCLC histology and bevacizumab toxicity and pemetrexed efficacy were observed. The development of the epidermal growth factor receptor (EGFR) tyrosine kinase inhibitors, erlotinib and gefitinib, and the subsequent identification of activating EGFR mutations, also led to a focused effort to better define the molecular characteristics of NSCLC. ${ }^{3-6}$ Finally, the recent development of crizotinib for patients with NSCLC and an anaplastic lymphoma kinase $(A L K)$ rearrangement demonstrated the necessity of identifying the molecular characteristics of NSCLC for the development of novel therapeutic agents. ${ }^{7-9}$ Together, these discoveries have shifted the simplistic binary lung cancer classification system to a refined 


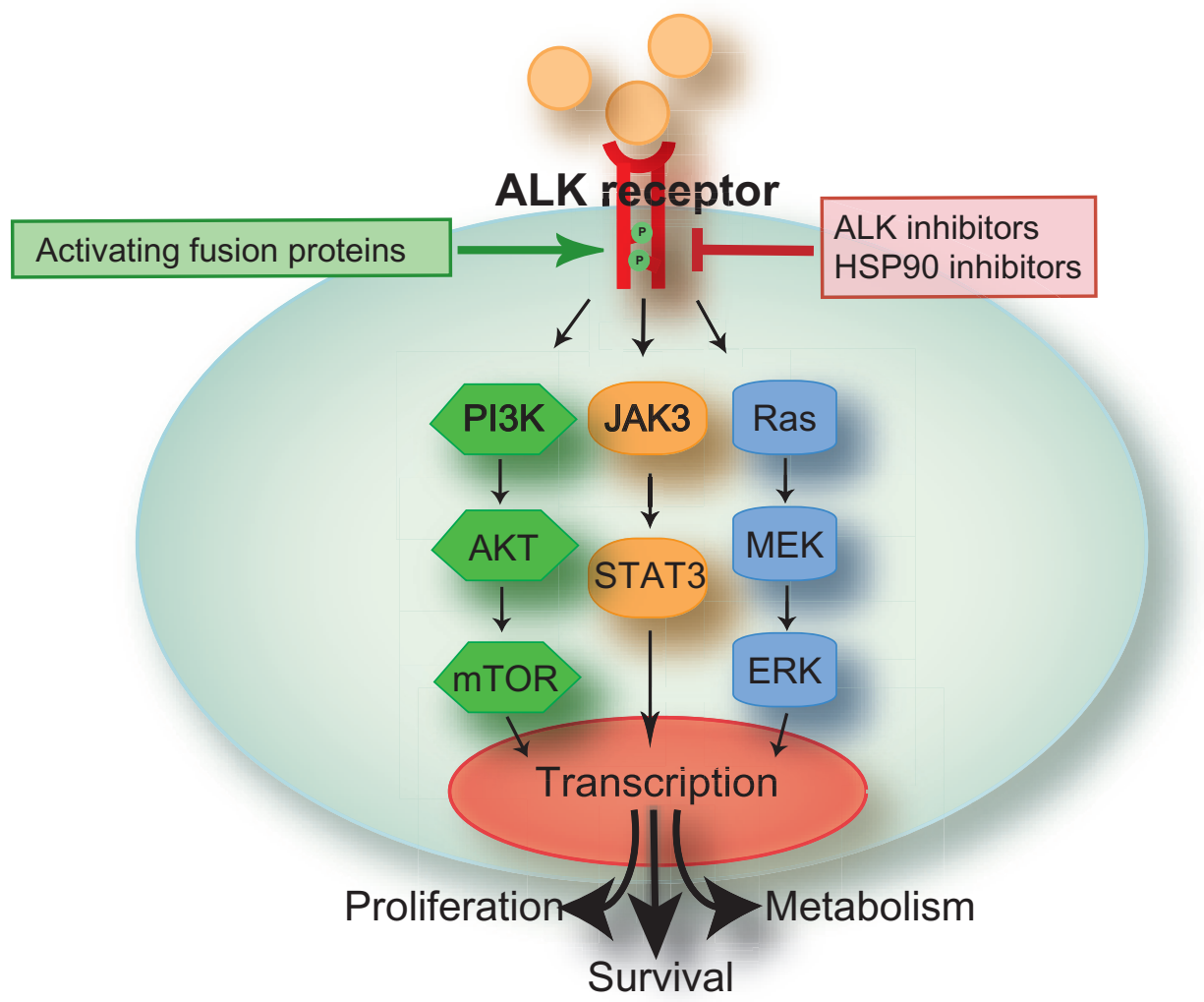

Figure I Aberrant ALK signaling cascade.

Notes: ALK gene rearrangements result in aberrant ALK signaling through PI3K/AKT/mTOR, JAK/STAT, and RAS/MEK/ERK signaling pathways. Constitutive ALK signaling mediates enhanced cell proliferation, cell survival, and metabolism. Current efforts to target aberrant ALK signaling in cancer include inhibition with ALK tyrosine kinase inhibitors and inhibition of the molecular chaperone heat shock protein 90, which leads to reduced ALK expression.

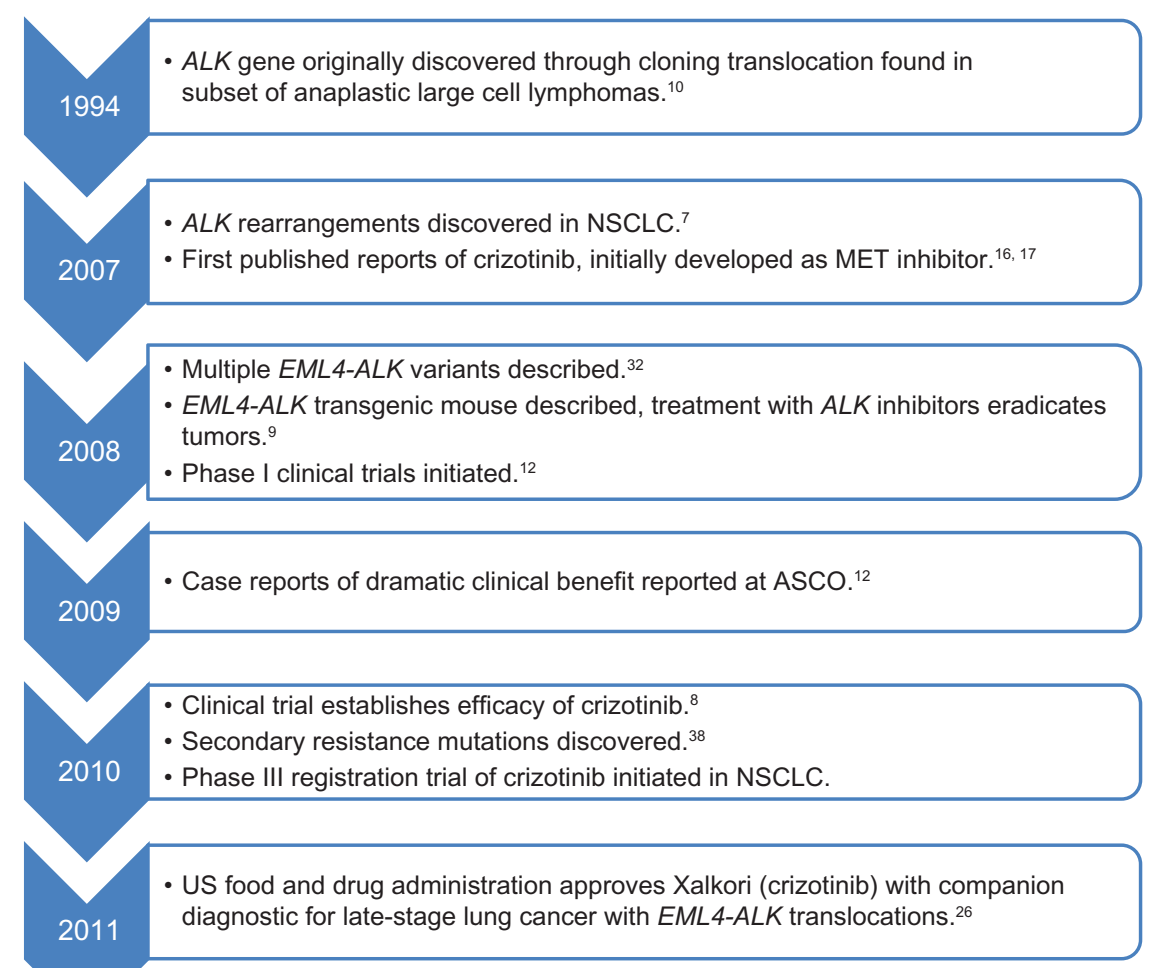

Figure 2 Major events leading to rapid clinical development of crizotinib for ALK-positive NSCLC.

Abbreviations: ALK, anaplastic lymphoma kinase; ASCO, American Society of Clinical Oncology; EML4-ALK, echinoderm microtubule-associated protein-like 4-anaplastic lymphoma kinase fusion-type tyrosine kinase; MET, met proto-oncogene (hepatocyte growth factor receptor); NSCLC, non-small cell lung cancer. 
classification system which defines the histological and molecular subsets of NSCLC.

The $A L K$ gene was originally discovered by cloning a translocation found in a subset of anaplastic large cell lymphomas. ${ }^{10}$ The presence of $A L K$ rearrangements in NSCLC were first reported in $2007^{7}$ and are present in $5 \%-7 \%$ of NSCLC patients. ${ }^{11-14}$ The activated ALK fusion proteins have been shown to drive oncogenic transformation through several molecular signaling pathways, ${ }^{15}$ including PI3K/AKT/mTOR, JAK/STAT, and RAS/MEK/ERK (Figure 1). The discovery of $A L K$ rearrangements in NSCLC serendipitously coincided with the development of crizotinib for other ALK or METdriven malignancies, ${ }^{16,17}$ allowing for expedited clinical development (Figure 2) and ultimately approval by the US Food and Drug Administration (FDA). This review will discuss the clinical development and use of crizotinib in NSCLC.

\section{Clinicopathological characteristics of EML4-ALK-positive patients}

NSCLC patients with $E M L 4-A L K$ rearrangements are associated with a specific pattern of patient characteristics. ${ }^{8,13,14}$ $A L K$-rearranged adenocarcinomas have a distinct histology that is dominated by a solid tumor growth pattern, signet-ring cells, and intracellular mucin; these features are common among gastric, colon, and breast adenocarcinomas, but rare in NSCLC. ${ }^{13}$ Patients affected are on average $10-15$ years younger than patients lacking an $A L K$ rearrangement and have a history of never having smoked or of former light smoking ( $\leq 10$ pack-years). ${ }^{8,13,14} A L K$ rearrangement, EGFR mutation, and $K R A S$ mutation are generally found to occur independently of one another and represent distinct molecular subsets, ${ }^{14}$ but concomitant $A L K$ rearrangements and EGFR mutations have been observed. ${ }^{18-23}$

Finally, the presence of $A L K$ rearrangement does not appear to be associated with ethnicity or gender, nor does there appear to be an association with time to progression or overall survival on combined platinum chemotherapy. ${ }^{14}$ The results evaluating the association with platinum-based chemotherapy will need to be confirmed in a larger study because the current analysis is limited by the presence of only a few patients with $A L K$ rearrangement and a lack of uniformity in the chemotherapy the patients received.

\section{Clinical development of crizotinib for NSCLC}

The use of single-agent crizotinib in the treatment of locally advanced or metastatic $A L K$-positive NSCLC was investigated in two multicenter, single-arm studies (studies A and B). ${ }^{24-26}$
As defined in the first-in-human Phase I trial of crizotinib, the maximally tolerated dose of $250 \mathrm{mg}$ of crizotinib orally twice daily ${ }^{12}$ was used in each of these trials. In study A, $A L K$-positive NSCLC was identified using the Vysis ALK break-apart fluorescence in situ hybridization (FISH) probe kit (Abbott Molecular Inc, Des Plaines, IL, USA), while study B identified $A L K$-positive patients using a number of local clinical trial assays. The primary efficacy endpoint in both studies was objective response rate using RECIST (Response Evaluation Criteria in Solid Tumors). In addition to objective response rate, both studies evaluated duration of response. At the time of regulatory submission, results from 136 patients were available from study A (Profile 1005), a global, multicenter, open-label, single-arm Phase II trial. ${ }^{25,26}$ All patients enrolled in study A had received prior systemic therapy. Of the 136 patients, there was one complete response and 67 partial responses for an objective response rate of 50\% (95\% confidence interval [CI] 42-59, Table 1). The investigators also reported a median duration of treatment of 22 weeks and a median duration of response of 41.9 weeks. Since the initial results were reported to the FDA, Profile 1005 has continued to enroll patients. As of June 2011, 439 patients were evaluable for safety and 255 were evaluable for tumor response. ${ }^{27} \mathrm{At}$ that time, the objective response rate was 53\% (95\% CI 47-60), median duration of treatment was 25 weeks (77\% still ongoing), median duration of response was 43 weeks, and progression-free survival was 8.5 months (95\% CI 6.2-9.9). ${ }^{27}$ At the time of data cutoff for regulatory submission, study B had enrolled 119 patients with locally advanced or metastatic $A L K$-positive NSCLC, of whom all but 15 patients had received prior systemic therapy. Of the 119 enrolled patients, there were two complete responses and 69 partial responses for an objective response rate of $61 \%(95 \%$ CI 52-70, Table 1). The median duration of treatment was 32 weeks and the median duration of response was 48.1 weeks. ${ }^{24,26}$ Study B has continued to enroll patients, and updated data from 143 response-evaluable patients showed 87 objective responses

Table I Efficacy data for approval by the US Food and Drug Administration ${ }^{24-26}$

\begin{tabular}{lll}
\hline & $\begin{array}{l}\text { Study A } \\
\text { (profile 1 005) }\end{array}$ & $\begin{array}{l}\text { Study B } \\
(\mathbf{A 8 0 8} \text { I 00 I) }\end{array}$ \\
\hline Enrolment $^{\mathrm{a}}$ & 136 & $\mathrm{II}(\mathrm{II})^{\mathrm{b}}$ \\
Complete responses & $\mathrm{I}(\mathrm{I} \%)$ & $2(2 \%)$ \\
Partial responses & $67(49 \%)$ & $69(59 \%)$ \\
ORR (CR + PR) & $50 \%$ & $61 \%$ \\
& $(95 \% \mathrm{Cl} 42-59)$ & $(95 \% \mathrm{Cl} 52-70)$ \\
Median duration of response & 41.9 weeks & 48.1 weeks
\end{tabular}

Notes: ${ }^{a}$ Enrolment at the time of regulatory submission; ${ }^{\circ} 19$ patients enrolled, but only II 6 evaluable. Response rates calculated based on 116 patients.

Abbreviations: $\mathrm{Cl}$, confidence interval; $\mathrm{CR}$, complete response; $\mathrm{ORR}$, overall response rate; $\mathrm{PR}$, partial response. 
(61\%, 95\% CI 52-69), including three complete responses and 84 partial responses. ${ }^{28}$ Median progression-free survival was 9.7 months (95\% CI 7.7-12.8). While median overall survival data are not mature at this time, the estimated overall survival at 6 and 12 months was $87.9 \%(95 \%$ CI 81.3-92.3) and 74.8 (95\% CI 66.4-81.5), respectively.

Based on the response rates from studies A and B, crizotinib was granted accelerated approval by the FDA for the treatment of patients with locally advanced or metastatic NSCLC which is $A L K$-positive by an FDA-approved test. ${ }^{26} \mathrm{As}$ a condition of the accelerated approval, further post-marketing testing to evaluate clinical outcomes and survival are required. There are now two randomized Phase III studies (Profile 1007 and Profile 1014) evaluating progression-free survival as the primary endpoint and overall survival as a secondary endpoint, while Profile 1007 is comparing crizotinib with pemetrexed or docetaxel as second-line therapy. Profile 1014 is comparing crizotinib with a platinum-pemetrexed combination in newly diagnosed $A L K$-positive patients with NSCLC.

An interim analysis of data from Profile 1007 was reported at the 2012 Congress of the European Society for Medical Oncology in Vienna, Austria. ${ }^{29}$ The study included 347 patients with $A L K$-positive lung cancer who had already been treated with chemotherapy. Patients were randomized to receive crizotinib or standard chemotherapy with pemetrexed or docetaxel. Crizotinib demonstrated a prolonged median progression-free survival of 7.7 months compared with 3 months among those patients who received chemotherapy. The objective response rate was also significantly higher in patients treated with crizotinib (65\%) compared with those treated with chemotherapy $(20 \%)$. Because of the nature of the early analysis, a statistically significant difference in overall survival was not yet seen. Because of significant crossover in the study, where patients in the chemotherapy arm who experienced disease progression were allowed to cross over to receive crizotinib, it may be difficult to see an overall survival benefit even after the data have matured. Finally, while investigators reported that crizotinib was associated with more adverse events than chemotherapy, patients treated with crizotinib reported improved quality of life compared with patients treated with chemotherapy. These results are very promising and suggest that crizotinib should be considered the new standard of care for patients with $A L K$-positive NSCLC.

\section{Clinical diagnostic techniques}

Unlike traditional chemotherapeutic agents, molecularly targeted therapies face the additional challenges of needing an understanding of the molecular target and having a validated test to detect the specific molecular alteration. For crizotinib, $A L K$ rearrangements were identified as the molecular target ${ }^{7,8}$ and the Vysis break-apart FISH probe kit was concurrently approved by the FDA as the companion diagnostic. ${ }^{30} \mathrm{In}$ support of the clinicopathological data, the National Comprehensive Cancer Network (NCCN) guidelines for NSCLC now recommend $A L K$ testing concurrently with $E G F R$ mutation testing for adenocarcinoma, large cell carcinoma, and not otherwise specified histological subtypes. ${ }^{30}$ The current guidelines do not recommend testing in NSCLC patients with squamous cell carcinoma. ${ }^{30}$

The Vysis ALK break-apart FISH probe kit is the only FDA-approved companion diagnostic to identify $A L K$-positive NSCLC patients. This test was the only assay used to identify and enroll patients with $A L K$ rearrangements into crizotinib clinical trials prospectively, and therefore is the only assay validated to correlate with crizotinib response. The break-apart FISH probe kit has been shown to be both highly sensitive and specific when using a cutoff of $>15 \%$ of cells and counting 60 cells. ${ }^{22}$ In addition to these features, the break-apart assay can be performed on formalin-fixed paraffin-embedded tissue, making it widely applicable, because almost all NSCLC tissue is formalin-fixed paraffin-embedded. Another advantage of this method is that it will detect all ALK rearrangements and is not specific for any particular fusion partner or variant. Despite all of these positive features, the $A L K$ FISH test has several disadvantages compared with other methods of detection. In a normal sample, the $5^{\prime}$ and $3^{\prime}$ ends of the $A L K$ gene are differently labeled with red and green fluorescent probes and are in close proximity to one another. However, in the presence of an $A L K$ rearrangement, the signals "break apart" from one another. The ability to detect the subtle change resulting from chromosomal inversion on chromosome $2 \mathrm{p}$ that produces $E M L 4-A L K$ fusion requires technical expertise, experience, and precise measurement. Without such experience and expertise, the altered probe hybridization patterns may be difficult to discern, leading to false negative results. ${ }^{13}$ In addition, the test is expensive and is not amenable to high throughput screening that would be ideal for testing the large number of samples needed to identify the few $A L K$-positive patients.

While the break-apart assay can confirm the presence of an $A L K$ rearrangement, it is not capable of defining the fusion partner or the precise fusion variant. However, realtime polymerase chain reaction is a highly specific method of defining the type of translocation present in a given patient sample. ${ }^{31}$ In addition to being the most sensitive method of detecting $A L K$ rearrangements, it also has the advantage of 
requiring limited material for analysis, ${ }^{32}$ is relatively easy to perform, and is less labor-intensive than FISH. However, the inability to extract sufficient quantity and quality RNA from formalin-fixed paraffin-embedded tissue is a major limitation of this methodology. In addition, even if an adequate RNA can be obtained, all known fusion partners ${ }^{33}$ must be known so that all primer sets are included in the analysis to ensure that no $A L K$-rearrangements are missed.

A third approach to identifying $A L K$-positive patients is immunohistochemistry. Because immunohistochemistry is routinely performed in every clinical pathology laboratory, ALK immunohistochemistry analysis could easily be incorporated into the normal staining performed during diagnosis and histological subtyping of NSCLC. As a low-cost and routine methodology, immunohistochemistry represents the ideal screen to identify the small subset of NSCLC patients harboring an $A L K$ rearrangement. The major hurdle facing the routine use of ALK immunohistochemistry is the availability of a reliable antibody. A commercially available ALK1 antibody (Dako, Glostrup, Denmark) is currently being used to identify $A L K$ rearrangements in anaplastic large cell lymphoma. However, the expression of ALK in NSCLC appears to be approximately five-fold lower than in anaplastic large cell lymphoma, ${ }^{34}$ possibly due to differences in the transcriptional activity of the promoter regions of their respective fusion partners (EML4 versus nucleophosmin). As a result, standard staining procedures for the ALK1 antibody have been shown to have a high rate of false negative results for identifying $A L K$ positive NSCLC. ${ }^{13,34,35}$ Amplification techniques to enhance the signal of ALK1 staining have been shown to improve immunohistochemistry detection of known $A L K$-positive samples. ${ }^{13,34,36}$ Alternative ALK antibodies, such as D5F3, have been shown to have higher sensitivity than the ALK1 antibody $^{34,36}$ and have demonstrated complete concordance with genetic data. ${ }^{34}$ While several alternative ALK antibodies have been tested, ${ }^{34,36}$ it appears that the D5F3 antibody is the front runner to gain acceptance as a cost-effective and rapid screening tool for identifying $A L K$-positive NSCLC patients. In early 2012, Ventana Medical Systems Inc (Tucson, AZ, USA) established a collaboration with Pfizer (New York, NY, USA) and a license agreement with Cell Signaling Technology (Beverly, MA, USA) to develop D5F3 as the first fully automated and standardized immunohistochemistry companion diagnostic test for $A L K$ gene rearrangements in NSCLC patients.

\section{Adverse events and precautions}

In clinical trials leading to FDA approval, the most common adverse reactions were vision disorders, nausea, diarrhea,
Table 2 Common adverse events reported in studies $A$ and $B$

\begin{tabular}{|c|c|c|}
\hline & $\begin{array}{l}\text { All grades } \\
\text { n (\%) }\end{array}$ & $\begin{array}{l}\text { Grades 3-4 } \\
\text { n (\%) }\end{array}$ \\
\hline \multicolumn{3}{|l|}{ Eye disorders } \\
\hline Visual disturbance & $159(62)$ & 0 \\
\hline \multicolumn{3}{|c|}{ Gastrointestinal disorders } \\
\hline Nausea & $136(53)$ & 0 \\
\hline Diarrhea & $109(43)$ & 0 \\
\hline Vomiting & $10 \mid(40)$ & 0 \\
\hline Constipation & $69(27)$ & $\mathrm{I}(<\mathrm{I})$ \\
\hline Esophageal disorder & $29(11)$ & 0 \\
\hline Abdominal pain & $20(8)$ & 0 \\
\hline \multicolumn{3}{|l|}{ General } \\
\hline Edema & $72(28)$ & 0 \\
\hline Fatigue & $51(20)$ & $4(2)$ \\
\hline Decreased appetite & $49(19)$ & 0 \\
\hline \multicolumn{3}{|c|}{ Nervous system disorders } \\
\hline Dizziness & $42(16)$ & 0 \\
\hline Neuropathy & $34(13)$ & $\mathrm{I}(<\mathrm{I})$ \\
\hline Dysgeusia & $30(12)$ & 0 \\
\hline \multicolumn{3}{|l|}{ Liver disorders } \\
\hline ALT elevation & $34(13)$ & $14(5)$ \\
\hline AST elevation & $24(9)$ & $5(2)$ \\
\hline \multicolumn{3}{|l|}{ Skin disorders } \\
\hline Rash & $25(10)$ & 0 \\
\hline \multicolumn{3}{|c|}{ Cardiovascular disorder } \\
\hline Bradycardia & $12(5)$ & 0 \\
\hline
\end{tabular}

Note: $\mathrm{n}=225$.

Abbreviations: ALT, alanine aminotransferase; AST, aspartate aminotransferase.

vomiting, edema, and constipation (Table 2) ${ }^{26}$ Of these, visual disturbances were seen in $60 \%-65 \%$ of cases and were primarily associated with the transition between light and dark. The most common disturbance includes transient light flashes in the peripheral vision lasting just a few seconds. Onset is generally seen within 2 weeks after initiating therapy, generally decreases in frequency with continued crizotinib use, and ceases following discontinuation of the drug. While not as frequent as the aforementioned adverse effects, other common side effects include sinus bradycardia (Table 2) and hematological toxicity (Table 3 ). Grade 1-2 sinus bradycardia has occurred in 5\% of patients (12 of 255) treated as part of studies A and B. ${ }^{24-26}$ It is generally profound (heart rate $\leq 45$ ) but asymptomatic and appears to be a pharmacodynamic effect of crizotinib exposure. ${ }^{37}$ Grade 3 or 4 lymphopenia, neutropenia, and thrombocytopenia occurred in $11.4 \%, 5.2 \%$, and $0.4 \%$ of patients, respectively. ${ }^{26}$ If a patient experiences grade 3 or 4 hematological toxicity, crizotinib should be withheld until complete blood cell counts return to grade $\leq 2$ (Table 3). For patients experiencing grade 4 myelosuppression, the dose should be reduced to $200 \mathrm{mg}$ twice daily when treatment is resumed. In the case of recurrent hematological toxicity, crizotinib should be withheld again until recovery to grade $\leq 2$, then resume at $250 \mathrm{mg}$ once daily. Crizotinib 
Table 3 Serious adverse events requiring crizotinib dose modification

\begin{tabular}{|c|c|c|}
\hline Toxicity & $n(\%)^{a}$ & $\begin{array}{l}\text { Recommended dose } \\
\text { modification }\end{array}$ \\
\hline Hematologic toxicity & $43(17)^{b}$ & \\
\hline Grade 3 & & $\begin{array}{l}\text { Withhold until recovery to } \\
\text { grade } \leq 2 \text {, resume at the } \\
\text { same dose schedule }\end{array}$ \\
\hline Grade 4 & & $\begin{array}{l}\text { Withhold until recovery to } \\
\text { grade } \leq 2 \text {, then resume at } \\
200 \mathrm{mg} \text { twice dailyc }\end{array}$ \\
\hline QTc prolongation & $4(1.3)^{d}$ & \\
\hline Grade 3 & & $\begin{array}{l}\text { Withhold until recovery to } \\
\text { grade } \leq 1 \text {, then resume at } \\
200 \mathrm{mg} \text { twice daily }\end{array}$ \\
\hline Grade 4 & & Permanently discontinue \\
\hline Hepatotoxicity & $19(7)^{\mathrm{e}}$ & \\
\hline $\begin{array}{l}\text { Grade } 3 \text { or } 4 \text { ALT or } \\
\text { AST elevation }\end{array}$ & & $\begin{array}{l}\text { Permanently discontinue } \\
\text { with grade } \leq \text { I total } \\
\text { bilirubin }\end{array}$ \\
\hline $\begin{array}{l}\text { Grade } 2,3 \text {, or } 4 \text { ALT or } \\
\text { AST elevation }\end{array}$ & & $\begin{array}{l}\text { Permanently discontinue } \\
\text { with grade } 2,3 \text {, or } \\
4 \text { total bilirubin }\end{array}$ \\
\hline Pulmonary toxicity & $4(1.6)$ & \\
\hline Pneumonitis (any grade) & & Permanently discontinue \\
\hline
\end{tabular}

Notes: alncidence of Grade 3 and 4 toxicities reported in study A and study B from a total of 255 evaluable patients; blymphopenia 29 (I I\%); neutropenia 13 (5\%); thrombocytopenia I $(<1 \%)$; in case of recurrence, withhold until recovery to grade $\leq 2$, then resume at $250 \mathrm{mg}$ once daily. Permanently discontinue in case of further grade 4 recurrence; ' four cases of QTc prolongation out of 308 evaluable patients have been documented; eGrade 3 or 4 ALT elevation, 14 (5\%); Grade 3 or 4 AST, $5(2 \%)$

Abbreviations: ALT, alanine aminotransferase; AST, aspartate aminotransferase.

should be permanently discontinued in the event of further grade 4 recurrence.

Although rare, three more serious adverse events have led to additional labeling under "warnings and precautions" on the package insert. ${ }^{26}$ First, crizotinib-induced hepatotoxicity, as measured by alanine aminotransferase increases, has been observed in $13 \%$ of patients, with grade 3 and 4 alanine aminotransferase increases occurring in $5 \%$ of patients (Table 3 ). While fatal hepatotoxicity is rare, occurring in less than $1 \%$ of patients in clinical trials, patients should be counseled to report to their physician immediately any symptoms of hepatotoxicity, such as weakness, fatigue, anorexia, nausea, vomiting, abdominal pain (especially right upper quadrant abdominal pain), jaundice, dark urine, generalized pruritus, and bleeding diathesis, especially in combination with fever and rash. Concurrent elevations in alanine aminotransferase greater than three times the upper limit of normal and total bilirubin greater than two times the upper limit of normal, with normal alkaline phosphatase, occurred in less than $1 \%$ of patients in clinical trials. Elevation in alanine aminotransferase greater than five times the upper limit of normal occurred in 7\% of patients in study A and in $4 \%$ of patients in study B. These laboratory findings were generally asymptomatic and reversible upon interruption of treatment. Most patients were able to resume treatment at a lower dose without recurrence of elevated liver enzymes; however, three patients from study A (2\%) and one patient from study B (less than 1\%) required permanent discontinuation of treatment. If grade 3 or 4 alanine aminotransferase or aspartate aminotransferase elevations are observed with concurrent grade $\leq 1$ bilirubin, then crizotinib should be held until laboratory investigations return to grade $\leq 1$ or baseline (Table 3 ). At that time, crizotinib can be restarted at $200 \mathrm{mg}$ twice daily. For more severe hepatotoxicity (grade 2-4 alanine aminotransferase or aspartate aminotransferase and grade $2-4$ bilirubin), crizotinib should be permanently discontinued. Routine monitoring with liver function tests including alanine aminotransferase and total bilirubin should be performed once a month and as clinically indicated. More frequent repeat testing should be performed in patients with increased liver transaminases, alkaline phosphatase, or total bilirubin, who develop further transaminase elevations.

Crizotinib has been associated with severe, life-threatening, or fatal treatment-related pneumonitis in 1.6\% (4 of 255) of patients across studies A and B (Table 3) ${ }^{24-26}$ Similar to other severe toxicities, all of the cases occurred within 2 months after initiation of treatment. Patients should be monitored for pulmonary symptoms indicative of pneumonitis, and crizotinib should be permanently discontinued in patients diagnosed with treatment-related pneumonitis.

QTc prolongation, while rare (1.3\%, 4 of 308 patients), has been observed. Therefore, crizotinib should be avoided in patients with congenital long QT syndrome. Monitoring at baseline and periodically thereafter with electrocardiography and electrolytes should be performed in patients with congestive heart failure, bradyarrhythmias, or electrolyte abnormalities, and in patients taking medications that are known to prolong the QT interval. Crizotinib should be permanently discontinued in patients who develop grade 4 QTc prolongation (Table 3). If a patient experiences a grade 3 QTe prolongation, the drug should be held until recovery to grade $\leq 1$. Once recovered, crizotinib may be resumed at $200 \mathrm{mg}$ twice daily. In case of recurrence of grade 3 QTc prolongation, withhold crizotinib until recovery to grade $\leq 1$, then resume crizotinib at $250 \mathrm{mg}$ once daily. In the event that grade 3 QTc prolongation recurs following dose reduction, crizotinib should be permanently discontinued. 


\section{Resistance}

Despite dramatic clinical responses following initiation of crizotinib therapy in patients with $A L K$-positive NSCLC, most of these patients will ultimately experience crizotinib failure and progressive disease within a year of starting treatment because of acquired drug resistance. Several mechanisms of crizotinib resistance have been described, including secondary $A L K$ mutations, ${ }^{18,38-42} A L K$ gene amplification, ${ }^{39-41}$ and activation of alternative oncogenes ( $E G F R, K I T, K R A S)$ via mutational activation, gene amplification, or autocrine signaling ${ }^{39,41,43}$ (Table 4). Secondary mutations within and around the kinase domain ATP-binding site are the most common mechanism of acquired resistance to tyrosine kinase inhibitors. ${ }^{44-46}$ This mechanism of drug resistance has been documented for inhibitors of BCR-ABL, EGFR, FLT3, KIT, and platelet-derived growth factor receptor. ${ }^{47}$ The most common mutation among these kinases takes place at the gatekeeper residue, where the size of the side chain of the amino acid at this position regulates the accessibility of the hydrophobic pocket located at the back of the Adenosine-5'-triphosphate (ATP)-binding site. ${ }^{47}$ Similar to the threonine at position 315 in ABL and at position 790 in EGFR, ${ }^{44}{ }^{46}$ the ALK L1196M mutation corresponds to this well described gatekeeper residue. Thus, all three of these mutations have been demonstrated to interfere with the binding of their respective tyrosine kinase inhibitors. ${ }^{38,44}{ }^{47}$ The other $A L K$ resistance mutations are located around the conformationally sensitive C-helix and activation loop, and may affect kinase activity and inhibitor binding through alterations in the structure or stability of these elements. For instance, substitution of a bulkier alanine at the glycine 1269 residue positioned at the end of the narrow ATP-binding pocket of ALK is thought to reduce the binding affinity of crizotinib as a result of steric hindrance. ${ }^{39}$ Further, while the L1152R and C1156Y mutations are not in contact with the ATP-binding cleft itself, they are in close proximity to it and adjacent to the C-helix. ${ }^{18}$ Therefore, these mutations may alter drug contact and/or create steric hindrance.

Table 4 Mechanisms of acquired crizotinib resistance

\begin{tabular}{ll}
\hline $\begin{array}{l}\text { Persistent presence of } \text { ALK } \\
\text { rearrangement }\end{array}$ & $\begin{array}{l}\text { Loss of detectable } A L K \\
\text { rearrangement }\end{array}$ \\
\hline Secondary ALK mutations & EGFR mutation \\
ALK copy number gain & KRAS mutation \\
Upregulation of ErbB signaling & Unknown \\
KIT amplification & \\
Unknown &
\end{tabular}

Abbreviations: ALK, anaplastic lymphoma kinase; EGFR, epidermal growth factor receptor; ErbB, avian erythroblastosis oncogene B homolog; KIT, v-kit Hardy-Zuckerman 4 feline sarcoma viral oncogene homolog; KRAS, v-Ki-ras2 Kirsten rat sarcoma viral oncogene homolog.
In addition to secondary mutations, several other mechanisms of acquired resistance have been described. In a series of $14 A L K$-positive NSCLC patients with documented disease progression while on crizotinib, of whom 11 had material for molecular analysis, only four were found to have secondary mutations. ${ }^{39}$ Two patients were found to have ALK copy number gain (one of which also had a secondary mutation). Mutations in EGFR and KRAS were identified in one and two patients, respectively. In total, this series was able to identify mechanisms of resistance in eight of 11 patients. A second series of $18 A L K$-positive NSCLC patients with documented disease progression while on crizotinib identified an array of secondary mutations in four patients and $A L K$ gene amplification in one patient. ${ }^{41}$ This study also confirmed the proposed EGFR-mediated resistance to crizotinib seen in preclinical models, ${ }^{41,43}$ by comparing pre-crizotinib and post-crizotinib tissue samples from nine patients. ${ }^{41}$ Using immunohistochemical staining for phospho-EGFR, EGFR activation was increased following the development of crizotinib resistance in four of nine samples. Finally, one patient's post-crizotinib tumor was found to have KIT gene amplification, increased KIT expression, and increased expression of the KIT ligand (stem cell factor), and a second patient's tumor was also shown to have KIT amplification. ${ }^{41}$

As new mechanisms of resistance continue to emerge, investigators have begun to identify novel approaches to treating patients who have developed crizotinib-resistant disease. There is a large group of second-generation ALK inhibitors in preclinical and clinical development (Table 5), some of which have been shown to be effective against specific common secondary mutations ${ }^{40,48,49}$ (Table 5). A second therapeutic approach to treating $A L K$-rearranged lung cancers with or without secondary mutations is through inhibition of the molecular chaperone, heat shock protein 90 . Heat shock protein 90 inhibitors bind in the ATP-binding pocket of the enzyme, and prevent it from regulating the activation and stability of its client proteins, including ALK. Inhibition of heat shock protein 90 has been shown to result in reduced expression of EML4-ALK, ${ }^{40,50}$ possibly through proteasomemediated degradation. ${ }^{51}$ This treatment approach is effective in both crizotinib-sensitive and crizotinib-resistant (due to secondary mutations) $A L K$-positive cell lines. ${ }^{40,41}$ While several heat shock protein 90 inhibitors (Table 5) have entered clinical development, there has not yet been a clinical trial that has selected patients with $A L K$-positive disease. Instead, clinical trials to date have tested heat shock protein 90 inhibitors in NSCLC patients with heterogeneous molecular subtypes. These trials have assessed 
Table 5 ALK-targeted therapies in development

\begin{tabular}{|c|c|c|c|}
\hline Drug & Manufacturer & Target & Clinical stage \\
\hline Crizotinib & Pfizer & ALK & $\begin{array}{l}\text { FDA approved; } \\
\text { Phase II }\end{array}$ \\
\hline AP26II3 & $\begin{array}{l}\text { Ariad } \\
\text { pharmaceuticals }\end{array}$ & ALK/EGFR ${ }^{a}$ & Phase I/II \\
\hline NMS-E628 & $\begin{array}{l}\text { Nerviano } \\
\text { medical }\end{array}$ & ALK & Preclinical \\
\hline$X-396$ & Xcovery & $\mathrm{ALK}^{\mathrm{b}}$ & Phase I \\
\hline $\mathrm{CH} 5424802$ & $\begin{array}{l}\text { Chugai } \\
\text { pharmaceuticals }\end{array}$ & $\mathrm{ALK}^{\mathrm{c}}$ & Phase I \\
\hline LDK378 & Novartis & ALK & Phase II \\
\hline ASP3026 & Astellas & ALK & Phase I \\
\hline $\begin{array}{l}\text { Ganetespib } \\
\text { (STA-9090) }\end{array}$ & $\begin{array}{l}\text { Synta } \\
\text { pharmaceuticals }\end{array}$ & HSP90 & Phase Ilb/III \\
\hline $\begin{array}{l}\text { Retaspimycin } \\
\text { (IPI-504) }\end{array}$ & $\begin{array}{l}\text { Infinity } \\
\text { pharmaceuticals }\end{array}$ & HSP90 & Phase II \\
\hline ATI3387 & $\begin{array}{l}\text { Astex } \\
\text { pharmaceuticals }\end{array}$ & HSP90 & Phase II \\
\hline AUY922 & Novartis & HSP90 & Phase II \\
\hline Debio 0932 & Debiopharma & HSP90 & Phase I/II \\
\hline $\begin{array}{l}\text { SNX-5422 } \\
\text { (PF-04929।।3) }\end{array}$ & Esanex & HSP90 & Phase I \\
\hline KW2478 & $\begin{array}{l}\text { Kyowa } \\
\text { Hakko Kirin }\end{array}$ & HSP90 & Phase I/II \\
\hline PU-H7I & $\begin{array}{l}\text { Samus } \\
\text { therapeutics }\end{array}$ & HSP90 & Phase I \\
\hline XL888 & Exelixis & HSP90 & Phase I \\
\hline DS-2248 & Daiichi Sankyo & HSP90 & Phase I \\
\hline BIIB028 & Biogen Idec & HSP90 & $\begin{array}{l}\text { Completed } \\
\text { Phase I }\end{array}$ \\
\hline NMS-P506 & Nerviano medical & HSP90 & Preclinical \\
\hline
\end{tabular}

Notes: ${ }^{a}$ Effective against LI 196M, SI206R, and GI269S ALK secondary mutations; beffective against LII96 ALK secondary mutations; 'effective against LII96M, CII56Y, and FII74L ALK secondary mutations.

Abbreviations: ALK, anaplastic lymphoma kinase; EGFR, epidermal growth factor receptor; HSP90, heat shock protein 90; FDA, US Food and Drug Administration.

common NSCLC genetic aberrations, including KRAS and $E G F R$ mutations, as well as $A L K$-rearrangements. In subset analysis of $A L K$-positive NSCLC patients (most of whom were crizotinib-naïve), heat shock protein 90 inhibitors have shown promising results. ${ }^{52-54}$ For instance, in a Phase II trial of the heat shock protein 90 inhibitor, ganetespib, four of eight (50\%) patients with advanced $A L K$-positive NSCLC experienced objective responses while receiving treatment with ganetespib monotherapy. ${ }^{54}$ In addition, the responses were durable, lasting an average of approximately one year. Finally, seven of eight patients (88\%) experienced disease control. Whether this approach will be as effective in patients with acquired crizotinib resistance remains to be seen and represents an important area of investigation. However, based on earlier results, the CHIARA trial (CHaperone Inhibition in ALK Rearranged lung cAncer) was initiated to evaluate ganetespib monotherapy in up to 110 patients with stage
IIIB/IV NSCLC harboring an $A L K$ gene rearrangement and who have not been previously treated with a direct ALK inhibitor (ie, crizotinib, clinicaltrials.gov, NCT01562015). Other potential therapeutic approaches to mitigate the development of acquired resistance or treat crizotinib-resistant disease are through dual inhibition of critical signaling pathways. For instance, a clinical trial evaluating the dual use of ganetespib and crizotinib in $A L K$-positive patients is currently enrolling patients (clinicaltrials.gov, NCT01579994). It will be interesting to see if this approach is more effective than either therapy alone and whether dual treatment prevents development of acquired resistance.

Other approaches include the combination of ALK inhibitors, such as crizotinib, with therapies targeting EGFR (erlotinib, clinicaltrials.gov, NCT00965731), PAN-EGFR family (dacomitinib, PF-00299804, clinicaltrials.gov, NCT01121575), or KIT. Finally, targeting downstream effector pathways, such as PI3K/AKT/mTOR and MEK/ERK, represents another therapeutic approach for treating tumors which have developed resistance to targeted receptor tyrosine kinase inhibitors, such as crizotinib. In a lapatinib-resistant HER2-driven breast cancer model, persistent PI3K/AKT/ mTOR and MEK/ERK signaling is maintained, and dual inhibition of these pathways has been shown to be an effective treatment strategy. ${ }^{55}$ While there is evidence that these pathways represent important signaling pathways involved in crizotinib resistance, it remains unclear how effective these various combinations will be and whether they should be used in the first-line setting or saved for use once crizotinib resistance has emerged.

\section{Crizotinib for other mutations (ROSI and MET)}

In addition to $A L K$-positive NSCLC, crizotinib may also be an effective treatment option for other molecular subsets of NSCLC. ROS1 is a receptor tyrosine kinase of the insulin receptor family. Chromosomal rearrangements involving the ROS1 gene were first described in glioblastoma and cholangiocarcinoma, ${ }^{56-58}$ and more recently in NSCLC..$^{59-61}$ Multiple ROS1 fusion partners have been indentified in NSCLC (TPM3, SDC4, SLC34A2, CD74, EZR, LRIG3, and $F I G^{60,61}$ ) and shown to fuse at exons $32,34,35$, or 36 of ROS1. These chimeric proteins maintain constitutive ROS1 kinase activity, leading to persistent downstream signaling and transforming ability via enhanced cell growth, proliferation, and decreased apoptosis.

ROS1 rearrangements have been found in approximately $1 \%-2 \%$ of NSCLC patients, ${ }^{61,62}$ thereby representing 
2000-4000 new cases of ROS1-positive NSCLC each year in the US. ROS1 rearrangements share several clinicopathological features with patients possessing $A L K$ rearrangements. Like $A L K$-positive NSCLC patients, ROS1-positive NSCLC patients tend to be younger (median age, 49.5 years), never-smokers, and have a histological diagnoses of adenocarcinoma. ${ }^{62}$ Additionally, ROS1 rearrangements are not found to overlap with other common NSCLC mutations, including EGFR mutations, KRAS mutations, or ALK rearrangements. ${ }^{62}$

Preclinical studies of cell lines harboring ROS1 rearrangements are sensitive to tyrosine kinase inhibitors, ${ }^{59,63}$ including the ALK inhibitor TAE684 ${ }^{64}$ and the dual ALK/MET inhibitor crizotinib. ${ }^{62}$ These observations were initially confirmed by a partial response in a single CD74-ROS1-positive NSCLC patient treated with crizotinib. ${ }^{62}$ However, a larger cohort of ROS1-positive NSCLC patients treated with crizotinib showed an objective response rate of $54 \%(7 / 13$, one complete response and six partial responses), with six responses achieved by the first restaging scan at 7-8 weeks after the initiation of therapy. ${ }^{65}$ The disease control rate (partial response + stable disease + complete response) at 8 weeks was $85 \%(11 / 13)$. Median duration of treatment was 20 weeks (range 4+ to 59+), and at the time of data cutoff for the report all responses were continuing on crizotinib. ${ }^{65}$

Patients with $M E T$ (mesenchymal-epithelial transition) mutations or amplifications represent another molecular subtype of NSCLC that may be responsive to crizotinib therapy. MET is a receptor tyrosine kinase, which signals via RAS, PI3K/AKT, and STAT to promote mitosis, survival, angiogenesis, migration, and invasion. ${ }^{66,67}$ While MET mutations are rare, MET amplification has been documented in $4 \%-11 \%$ of NSCLCs, ${ }^{68-72}$ making it an attractive drug target. Several MET-specific therapies are currently in clinical trials, such as tivantinib (ARQ 197) and MetMab. ${ }^{71}$ However, while the clinical development of crizotinib initially led to its approval by the FDA for $A L K$ positive NSCLC, it too was originally developed as a MET inhibitor and has demonstrated excellent in vitro activity, with an $\mathrm{IC}_{50}$ (half maximal inhibitory concentration) of $8 \mathrm{nM}$ against MET. Although comprehensive clinical data are lacking to support its efficacy in treating $M E T$-driven NSCLC, a recent case report ${ }^{72}$ has demonstrated a rapid and durable response to crizotinib in an NSCLC patient with de novo MET amplification and lacking an $A L K$ rearrangement. While this report only represents one patient, the findings are intriguing and suggest that crizotinib may be effective in MET-amplified NSCLC, as has been shown for other MET-amplified cancers. ${ }^{73,74}$

\section{Summary}

The clinical development of crizotinib has been an amazing success story in translational medicine that relied on the prior clinical experience of other targeted predecessors (ie, erlotinib in EGFR-mutant NSCLC) and a compound ready for clinical development to gain expedited FDA approval. While we await completion of the Phase III clinical trials, early results suggest crizotinib should be considered the standard of care for the firstline treatment of $A L K$-positive NSCLC patients, ${ }^{29}$ and possibly NSCLC patients with other genetic aberrations (ROS1 rearrangements or $M E T$ amplification). While crizotinib has demonstrated a dramatic clinical response in patients with $A L K$-positive NSCLC, patients will ultimately develop acquired resistance to crizotinib. Therefore, additional therapeutic approaches to prevent acquired resistance to crizotinib or effectively treat crizotinib-resistant disease are greatly needed.

\section{Acknowledgment}

This work was supported by the American Cancer Society (PF-10-239-01-TBG).

\section{Disclosure}

The author reports no conflicts of interest in this work.

\section{References}

1. Jemal A, Bray F, Center MM, Ferlay J, Ward E, Forman D. Global cancer statistics. CA Cancer J Clin. 2011;61(2):69-90.

2. Jemal A, Siegel R, Xu J, Ward E. Cancer statistics, 2010. CA Cancer J Clin. 2010;60(5):277-300.

3. Kim ES, Hirsh V, Mok T, al. Gefitinib versus docetaxel in previously treated non-small-cell lung cancer (INTEREST): a randomised phase III trial. Lancet. 2008;372(9652):1809-1818.

4. Lynch TJ, Bell DW, Sordella R, et al. Activating mutations in the epidermal growth factor receptor underlying responsiveness of non-small-cell lung cancer to gefitinib. N Engl J Med. 2004;350(21):2129-2139.

5. Paez JG, Jänne PA, Lee JC, et al. EGFR mutations in lung cancer: correlation with clinical response to gefitinib therapy. Science. 2004; 304(5676):1497-1500.

6. Shepherd FA, Rodrigues Pereira J, Ciuleanu T, et al. Erlotinib in previously treated non-small-cell lung cancer. $N$ Engl J Med. 2005; 353(2):123-132.

7. Soda M, Choi YL, Enomoto M, et al. Identification of the transforming EML4-ALK fusion gene in non-small-cell lung cancer. Nature. 2007;448(7153):561-566.

8. Kwak EL, Bang YJ, Camidge DR, et al. Anaplastic lymphoma kinase inhibition in non-small-cell lung cancer. $N$ Engl J Med. 2010;363(18): 1693-1703.

9. Soda M, Takada S, Takeuchi K, et al. A mouse model for EML4ALK-positive lung cancer. Proc Natl Acad Sci U S A. 2008;105(50): 19893-19897.

10. Morris SW, Kirstein MN, Valentine MB, et al. Fusion of a kinase gene, ALK, to a nucleolar protein gene, NPM, in non-Hodgkin's lymphoma. Science. 1994;263(5151):1281-1284.

11. Kris MG, Johnson BE, Kwiatkowski DJ, et al. Identification of driver mutations in tumor specimens from 1,000 patients with lung adenocarcinoma: the NCI's Lung Cancer Mutation Consortium (LCMC). J Clin Oncol. 2011;29 Suppl:Abstr CRA7506. 
12. Kwak EL, Camidge DR, Clark J, et al. Clinical activity observed in a phase I dose escalation trial of an oral c-met and ALK inhibitor, PF-02341066. J Clin Oncol. 2009;27 Suppl:148s.

13. Rodig SJ, Mino-Kenudson M, Dacic S, et al. Unique clinicopathologic features characterize ALK rearranged lung adenocarcinoma in the western population. Clin Cancer Res. 2009;15(16):5216-5223.

14. Shaw AT, Yeap BY, Mino-Kenudson M, et al. Clinical features and outcome of patients with non small-cell lung cancer who harbor EML4ALK. J Clin Oncol. 2009;27(26):4247-4253.

15. Chiarle R, Voena C, Ambrogio C, Piva R, Inghirami G. The anaplastic lymphoma kinase in the pathogenesis of cancer. Nat Rev Cancer. 2008;8(1):11-23.

16. Christensen JG, Zou HY, Arango ME, et al. Cytoreductive antitumor activity of PF-2341066, a novel inhibitor of anaplastic lymphoma kinase and c-Met, in experimental models of anaplastic large-cell lymphoma. Mol Cancer Ther. 2007;6(12 Pt 1):3314-3322.

17. Zou HY, Li Q, Lee JH, et al. An orally available small-molecule inhibitor of c-Met, PF-2341066, exhibits cytoreductive antitumor efficacy through antiproliferative and antiangiogenic mechanisms. Cancer Res. 2007;67(9):4408-4417.

18. Sasaki T, Koivunen J, Ogino A, et al. A novel ALK secondary mutation and EGFR signaling cause resistance to ALK kinase inhibitors. Cancer Res. 2011;71(18):6051-6060.

19. Tiseo M, Gelsomino F, Boggiani D, et al. EGFR and EML4-ALK gene mutations in NSCLC: A case report of erlotinib-resistant patient with both concomitant mutations. Lung Cancer. 2011;71(2):241-243.

20. Wallander ML, Geiersbach KB, Tripp SR, Layfield LJ. Comparison of reverse transcription-polymerase chain reaction, immunohistochemistry, and fluorescence in situ hybridization methodologies for detection of echinoderm microtubule-associated proteinlike 4-anaplastic lymphoma kinase fusion-positive non-small cell lung carcinoma: Implications for optimal clinical testing. Arch Pathol Lab Med. 2012;136(7):796-803.

21. Yang J, Zhang X, Su J, et al. Concomitant EGFR mutation and EML4-ALK gene fusion in non-small cell lung cancer. J Clin Oncol. 2011;29(Suppl 15):10517.

22. Camidge DR, Kono SA, Flacco A, et al. Optimizing the detection of lung cancer patients harboring anaplastic lymphoma kinase (ALK) gene rearrangements potentially suitable for ALK inhibitor treatment. Clin Cancer Res. 2010;16(22):5581-5590.

23. Zhang X, Zhang S, Yang X, et al. Fusion of EML4 and ALK is associated with development of lung adenocarcinomas lacking EGFR and KRAS mutations and is correlated with ALK expression. Mol Cancer. 2010;9:188.

24. Camidge DR, Bang Y, Kwak EL, et al. Progression-free survival (PFS) from a Phase I study of crizotinib (PF-02341066) in patients with ALKpositive non-small cell lung cancer (NSCLC). J Clin Oncol. 2011; 29(Suppl 15):2501.

25. Crino L, Crinò L, Kim D, et al. Initial phase II results with crizotinib in advanced ALK-positive non-small cell lung cancer (NSCLC): Profile 1005. J Clin Oncol. 2011;29 Suppl:Abstr 7514.

26. Xalkori [crizotinib, package insert]. New York, NY: Pfizer Inc; 2011.

27. Kim DW, Ahn MJ, Shi Y, et al. Results of a global phase II study with crizotinib in advanced ALK-positive non-small cell lung cancer (NSCLC). J Clin Oncol. 2012;30 Suppl:Abstr 7533.

28. Camidge DR, Bang YJ, Kwak EL, et al. Activity and safety of crizotinib in patients with ALK-positive non-small-cell lung cancer: updated results from a Phase 1study. Lancet Oncol. 2012;13(10): 1011-1019.

29. Shaw AT, Kim DW, Nakagawa K, et al. Phase III study of crizotinib versus pemetrexed or docetaxel chemotherapy in patients with advanced ALKpositive non-small cell lung cancer (NSCLC) (PROFILE 1007). Abstract LBA1 presented at the Annual Congress of the European Society for Medical Oncology, Vienna, Austria, September 28-October 2, 2012.

30. Shaw AT, Solomon B, Kenudson MM. Crizotinib and testing for ALK. J Natl Compr Canc Netw. 2011;9(12):1335-1341.
31. Takeuchi K, Choi YL, Soda M, et al. Multiplex reverse transcriptionPCR screening for EML4-ALK fusion transcripts. Clin Cancer Res. 2008;14(20):6618-6624.

32. Nakajima T, Kimura H, Takeuchi K, et al. Treatment of lung cancer with an ALK inhibitor after EML4-ALK fusion gene detection using endobronchial ultrasound-guided transbronchial needle aspiration. J Thorac Oncol. 2010;5(12):2041-2043.

33. Choi YL, Takeuchi K, Soda M, et al. Identification of novel isoforms of the EML4-ALK transforming gene in non-small cell lung cancer. Cancer Res. 2008;68(13):4971-4976.

34. Mino-Kenudson M, Chirieac LR, Law K, et al. A novel, highly sensitive antibody allows for the routine detection of ALK-rearranged lung adenocarcinomas by standard immunohistochemistry. Clin Cancer Res. 2010;16(5):1561-1571.

35. Martelli MP, Sozzi G, Hernandez L, et al. EML4-ALK rearrangement in non-small cell lung cancer and non-tumor lung tissues. Am J Pathol. 2009;174(2):661-670.

36. Takeuchi K, Choi YL, Togashi Y, et al. KIF5B-ALK, a novel fusion oncokinase identified by an immunohistochemistry-based diagnostic system for ALK-positive lung cancer. Clin Cancer Res. 2009;15(9):3143-3149.

37. Ou SH, Azada M, Dy J, Stiber JA. Asymptomatic profound sinus bradycardia (heart rate $\leq 45$ ) in non-small cell lung cancer patients treated with crizotinib. J Thorac Oncol. 2011;6(12):2135-2137.

38. Choi YL, Soda M, Yamashita Y, et al; ALK Lung Cancer Study Group. EML4-ALK mutations in lung cancer that confer resistance to ALK inhibitors. N Engl J Med. 2010;363(18):1734-1739.

39. Doebele RC, Pilling AB, Aisner DL, et al. Mechanisms of resistance to crizotinib in patients with ALK gene rearranged non-small cell lung cancer. Clin Cancer Res. 2012;18(5):1472-1482.

40. Katayama R, Khan TM, Benes C, et al. Therapeutic strategies to overcome crizotinib resistance in non-small cell lung cancers harboring the fusion oncogene EML4-ALK. Proc Natl Acad Sci U SA. 2011;108(18): $7535-7540$.

41. Katayama R, Shaw AT, Khan TM, et al. Mechanisms of acquired crizotinib resistance in ALK-rearranged lung cancers. Sci Transl Med. 2012;4(120):120ra17.

42. Sasaki T, Okuda K, Zheng W, et al. The neuroblastoma-associated F1174L ALK mutation causes resistance to an ALK kinase inhibitor in ALK-translocated cancers. Cancer Res. 2010;70(24):10038-10043.

43. Tanizaki J, Okamoto I, Okabe T, et al. Activation of HER family signaling as a mechanism of acquired resistance to ALK inhibitors in EML4ALK-positive non-small cell lung cancer. Clin Cancer Res. 2012; 18(22):6219-6226.

44. Gorre ME, Mohammed M, Ellwood K, et al. Clinical resistance to STI571 cancer therapy caused by BCR-ABL gene mutation or amplification. Science. 2001;293(5531):876-880.

45. Pao W, Miller VA, Politi KA, et al. Acquired resistance of lung adenocarcinomas to gefitinib or erlotinib is associated with a second mutation in the EGFR kinase domain. PLoS Med. 2005;2(3):e73.

46. Kwak EL, Sordella R, Bell DW, et al. Irreversible inhibitors of the EGF receptor may circumvent acquired resistance to gefitinib. Proc Natl Acad Sci U S A. 2005;102(21):7665-7670.

47. Zhang J, Yang PL, Gray NS. Targeting cancer with small molecule kinase inhibitors. Nat Rev Cancer. 2009;9(1):28-39.

48. Lovly CM, Heuckmann JM, de Stanchina E, et al. Insights into ALKdriven cancers revealed through development of novel ALK tyrosine kinase inhibitors. Cancer Res. 2011;71(14):4920-4931.

49. Sakamoto H, Tsukaguchi T, Hiroshima S, et al. CH5424802, a selective ALK inhibitor capable of blocking the resistant gatekeeper mutant. Cancer Cell. 2011;19(5):679-690.

50. Chen Z, Sasaki T, Tan X, et al. Inhibition of ALK, PI3K/MEK, and HSP90 in murine lung adenocarcinoma induced by EML4-ALK fusion oncogene. Cancer Res. 2010;70(23):9827-9836.

51. Neckers L, Workman P. Hsp90 molecular chaperone inhibitors: are we there yet? Clin Cancer Res. 2012;18(1):64-76. 
52. Goss GD, et al. The GALAXY trial (NCT01348126): a randomized IIB/III study of ganetespib (STA-9090) in combination with docetaxel versus docetaxel alone in subjects with stage IIIB or IV NSCLC. J Clin Oncol. 2012;30(Suppl 15):TPS7613.

53. Sequist LV, Gettinger S, Senzer NN, et al. Activity of IPI-504, a novel heat-shock protein 90 inhibitor, in patients with molecularly defined non-small-cell lung cancer. J Clin Oncol. 2010;28(33):4953-4960.

54. Wong K, Koczywas M, Goldman JW, et al. An open-label Phase II study of the Hsp90 inhibitor ganetespib (STA-9090) as monotherapy in patients with advanced non-small cell lung cancer (NSCLC). J Clin Oncol. 2011;29 Suppl:Abstr 7500.

55. Roberts PJ, Usary JE, Darr DB, et al. Combined PI3K/mTOR and MEK inhibition provides broad antitumor activity in faithful murine cancer models. Clin Cancer Res. 2012;18(19):5290-5303.

56. Charest A, Lane K, McMahon K, et al. Fusion of FIG to the receptor tyrosine kinase ROS in a glioblastoma with an interstitial del(6) (q21q21). Genes Chromosomes Cancer. 2003;37(1):58-71.

57. Gu TL, Deng X, Huang F, et al. Survey of tyrosine kinase signaling reveals ROS kinase fusions in human cholangiocarcinoma. PLoS One. 2011;6(1):e15640.

58. Sharma S, Birchmeier C, Nikawa J, O’Neill K, Rodgers L, Wigler M. Characterization of the ros 1-gene products expressed in human glioblastoma cell lines. Oncogene Res. 1989;5(2):91-100.

59. Rikova K, Guo A, Zeng Q, et al. Global survey of phosphotyrosine signaling identifies oncogenic kinases in lung cancer. Cell. 2007;131(6):1190-1203.

60. Rimkunas VM, Crosby KE, Li D, et al. Analysis of receptor tyrosine kinase ROS1-positive tumors in non-small cell lung cancer: identification of a FIG-ROS1 fusion. Clin Cancer Res. 2012;18(16):4449-4457.

61. Takeuchi K, Soda M, Togashi Y, et al. RET, ROS1 and ALK fusions in lung cancer. Nat Med. 2012;18(3):378-381.

62. Bergethon K, Shaw AT, Ou SH, et al. ROS1 rearrangements define a unique molecular class of lung cancers. J Clin Oncol. 2012; 30(8):863-870.

63. Yasuda $\mathrm{H}$, et al. Preclinical rationale for use of the clinically available multitargeted tyrosine kinase inhibitor crizotinib in ROS1-translocated lung cancer. J Thorac Oncol. 2012;7(7):p. 1086-1090.
64. McDermott U, et al. Genomic alterations of anaplastic lymphoma kinase may sensitize tumors to anaplastic lymphoma kinase inhibitors. Cancer Res. 2008;68(9):p. 3389-3395.

65. Shaw AT, et al., Clinical activity of crizotinib in advanced non-small cell lung cancer (NSCLC) harboring ROS1 gene rearrangement. ASCO Meeting Abstracts. 2012;30(15_suppl):p. 7508.

66. Feng Y, Thiagarajan PS, Ma PC. MET signaling: novel targeted inhibition and its clinical development in lung cancer. $J$ Thorac Oncol. 2012;7(2):p. 459-467.

67. Ma PC, et al. c-Met: structure, functions and potential for therapeutic inhibition. Cancer Metastasis Rev. 2003;22(4):p. 309-325.

68. Chen YT, et al. Clinical implications of high MET gene dosage in non-small cell lung cancer patients without previous tyrosine kinase inhibitor treatment. J Thorac Oncol. 2011;6(12):p. 2027-2035.

69. Dziadziuszko R, et al. Correlation between MET gene copy number by silver in situ hybridization and protein expression by immunohistochemistry in non-small cell lung cancer. JThorac Oncol. 2012;7(2):p. 340-347.

70. Park, S., et al., High MET copy number and MET overexpression: poor outcome in non-small cell lung cancer patients. Histol Histopathol, 2012. 27(2): p. 197-207.

71. Vincent MD, et al., Biomarkers that currently affect clinical practice: EGFR, ALK, MET, KRAS. Curr Oncol. 2012;19(Suppl 1):p. S33-S44.

72. Ou SH, et al. Activity of crizotinib (PF02341066), a dual mesenchymalepithelial transition (MET) and anaplastic lymphoma kinase (ALK) inhibitor, in a non-small cell lung cancer patient with de novo MET amplification. J Thorac Oncol. 2011;6(5):p. 942-946.

73. Chi AS, et al. Clinical improvement and rapid radiographic regression induced by a MET inhibitor in a patient with MET-amplified glioblastoma. ASCO Meeting Abstracts. 2012;29(15_suppl):p. 2072.

74. Lennerz JK, et al. MET amplification identifies a small and aggressive subgroup of esophagogastric adenocarcinoma with evidence of responsiveness to crizotinib. J Clin Oncol. 2011;29(36):p. 4803-4810.
Biologics: Targets \& Therapy

\section{Publish your work in this journal}

Biologics: Targets \& Therapy is an international, peer-reviewed journal focusing on the patho-physiological rationale for and clinical application of Biologic agents in the management of autoimmune diseases, cancers or other pathologies where a molecular target can be identified This journal is indexed on PubMed Central, CAS, EMBase, Scopus

\section{Dovepress}

and the Elsevier Bibliographic databases. The manuscript management system is completely online and includes a very quick and fair peerreview system, which is all easy to use. Visit http://www.dovepress. $\mathrm{com} /$ testimonials.php to read real quotes from published authors. 